Article

\title{
Development of Novel Magneto-Biosensor for Sulfapyridine Detection
}

Talha Jamshaid ${ }^{1,2,3}$, Ernandes Taveira Tenório-Neto ${ }^{2,4} \mathbb{D}^{\mathbb{D}}$, Abdoullatif Baraket ${ }^{1}$,

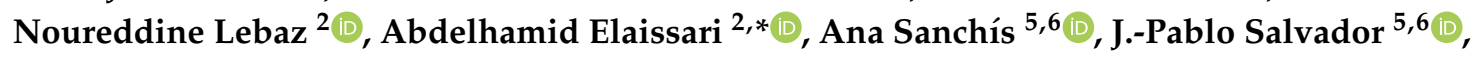
M.-Pilar Marco ${ }^{5,6}{ }^{\circledR}$, Joan Bausells ${ }^{7}{ }^{\circ}$, Abdelhamid Errachid ${ }^{1, *}$ and Nadia Zine ${ }^{1}$

1 Institut des Sciences Analytiques, University Claude Bernard Lyon-1, UMR 5280, 5 rue de la Doua, F-69100 Villeurbanne, France; talhajamshaid007@gmail.com (T.J.); a.baraket@gmail.com (A.B.); Nadia.zine@univ-lyon1.fr (N.Z.)

2 University Claude Bernard Lyon-1, CNRS, LAGEPP UMR-5007, 43 Boulevard du 11 Novembre 1918, F-69100 Villeurbanne, France; tenorioernandes@gmail.com (E.T.T.-N.);

noureddine.lebaz@univ-lyon1.fr (N.L.)

3 Faculty of Pharmacy and Alternatives Medicins, The Islamia University of Bahawalpur, Bahawalpur 63100, Pakistan

4 Department of Chemistry, State University of Ponta Grossa, Av. Gen. Carlos Cavalcanti, 4748, CEP 84030-900 Ponta Grossa, Paraná, Brazil

5 Nanobiotechnology for Diagnostics (Nb4D), Department of Chemical and Biomolecular Nanotechnology, Institute for Advanced Chemistry of Catalonia (IQAC) of the Spanish Council for Scientific Research (CSIC), Jordi Girona 18-26, 08034 Barcelona, Spain; asvnqb@iqac.csic.es (A.S.); jpablo.salvador@iqac.csic.es (J.-P.S.); pilar.marco@cid.csic.es (M.-P.M.)

6 CIBER de Bioingeniería, Biomateriales y Nanomedicina (CIBER-BBN), Jordi Girona 18-26, 08034 Barcelona, Spain

7 Institute of Microelectronics of Barcelona (IMB-CSIC), Universitat Autònoma de Barcelona (UAB), Bellaterra, 08193 Barcelona, Spain; joan.bausells@imb-cnm.csic.es

* Correspondence: abdelhamid.elaissari@univ-lyon1.fr (A.E.); abdelhamid.errachid-el-salhi@univ-lyon1.fr (A.E.)

Received: 25 March 2020; Accepted: 17 April 2020; Published: 21 April 2020

Abstract: In this work, we report the development of a highly sensitive biosensor for sulfapyridine detection based on an integrated bio micro-electromechanical system (Bio-MEMS) containing four gold working electrodes (WEs), a platinum counter electrode (CE), and a reference electrode (RE). Firstly, the cleaned WEs were modified with 4-aminophenylacetic acid (CMA). Then, (5-[4-(amino)phenylsulfonamide]-5-oxopentanoic acid (SA2BSA) was immobilized onto the transducers surface by carbodiimide chemistry. The analyte was quantified by competitive detection with SA2BSA immobilized on the WE toward a mixture of Ab155 antibody (with fixed concentration) and sulfapyridine. In order to obtain a highly sensitive biosensor, Ab155 was immobilized onto magnetic latex nanoparticles surface to create a 3D architecture (Ab-MLNp). Using electrochemical impedance spectroscopy (EIS), we investigated the influence of the Ab-MLNp on the sensitivity of our approach. The optimized system was analyzed, as competitive assay, with different concentrations of sulfapyridine $(40 \mu \mathrm{M}, 4 \mu \mathrm{M}$, and $2 \mathrm{nM})$ and with phosphate buffer solution. From data fitting calculations and graphs, it was observed that the EIS showed more linearity when Ab-MLNp was used. This result indicates that the magnetic latex nanoparticles increased the sensitivity of the biosensor.

Keywords: biosensor; sulfapyridine; SA2BSA; BioMEMS; magnetic nanoparticles; competitive assay 


\section{Introduction}

Increasing attention has been paid to antibiotics as aquatic micropollutants with their environmental fate and impact to be understood [1]. Sulfonamide antibiotics (SAs), as one of the most important classes of antibiotics, are widely used in aquaculture, livestock husbandry, and human medicine. Recently, SAs were detected ubiquitously in the aquatic environment, which may pose risks toward organisms [2-4]. Among the SAs, sulfapyridine, which is commonly used in aquaculture, was frequently detected in various environmental waters (e.g., wastewater effluents and receiving water bodies as well as fish farms and adjacent water bodies) [5]. For the detection of sulfapyridine, various methods have been used, such as chromatographic methods (likely high-performance liquid chromatography coupled with mass spectrometric detection (HPLC-MS)). Such methods have been applied due to their sensitivity and compound quantification data. Sample preparation is required using commercially available cartridges for solid-phase extraction. Additionally, other techniques have been employed, such as thin layer chromatography, gas chromatography (GC), liquid chromatography (LC) (including their variations coupled with mass spectrometry), and radio-active immune receptor for purpose of foodstuffs [6-8]. However, the above-mentioned approaches are time consuming and require complex sample preparation procedures, expensive laboratory equipment, and skilled professionals to handle these techniques.

In this sense, biosensors may offer cost-effective solutions for analyte detection. The biosensor is a compact analytical device or unit incorporating a biological (or biologically) derived sensitive element associated with a physicochemical transducer. They have revolutionized modern analysis due to their technical simplicity, low cost, and the possibility of being employed in field analysis $[9,10]$. The detection of sulfonamides using biosensors was previously demonstrated in different works [11-13]. However, few examples can be found using impedance spectroscopy for SA detection.

To improve the biosensor sensitivity, recently, magnetic nanoparticles (MNP) were produced as labels for biosensing. For the biosensing purpose, different types of biosensors were produced, such as giant-magnetoresistive (GMR) sensors and spin valves (SV) cantilevers [14,15], inductive sensors [16], superconducting quantum interference devices (SQUIDs) [17], anisotropic-magnetoresistive (AMR) rings, and miniature Hall crosses [18]. The detection of biological molecules is usually achieved by using biomolecular recognition between the target molecule and a specific receptor as, for example, an antibody that is tagged with a label.

In this context, superparamagnetic iron oxide nanoparticles (SPIONs) have been used as carriers for immobilization of biomolecules, such as peptides, proteins, and antibodies, to enhance the specific capture of the targeted biomolecules [19]. For preparing structured SPIONs with well-defined surface properties, specific functional groups, and better colloidal stability, several approaches have been investigated, including seeded-emulsion polymerization [20,21]. Using such an approach, magnetic latex nanoparticles with high iron oxide content can be obtained. These particles have reactive functional groups to form conjugates with various biomolecules (e.g., proteins, antibodies, DNA, and so forth), making them promising candidates to improve automation. Furthermore, the magnetic latex particles can enhance the diagnosis sensitivity by increasing the concentration of the captured targets [22].

Herein, an alternative procedure for sulfapyridine detection is proposed. Our approach consists of the development of bio-micro-electro-mechanical system (Bio-MEMS) transducers based on four gold micro-working electrodes ( $\mu \mathrm{WE}$ ) with fully integrated reference (RE) and platinum counter electrodes (CE). The surface of $\mu \mathrm{WE}$ was modified with coating antigen (5-[4-(amino)phenylsulfonamide]-5-oxopentanoic acid (SA2BSA), and the quantification of sulfapyridine was achieved through competitive assay toward antibodies Ab-155 deposited onto the magnetic latex nanoparticles surface. In addition, to evidence our proof of concept, we also compared the results obtained from our approach with those obtained from the competitive detection without magnetic latex particles. 


\section{Materials and Methods}

\subsection{Reagents and Apparatus}

The 4-aminophenylacetic acid 98\%, the N-Hydroxysuccinimide (NHS), and the 1-Ethyl-3-(3-dimethylaminopropyl)carbodiimide (EDC) were purchased from Acros Organics. Sodium nitrite was acquired from Fisher Scientific. Triton X-405 and phosphate buffer saline tablet were acquired from Sigma, ethanolamine from Fluka analytical, and hydrochloric acid $37 \%(\mathrm{HCl})$ from VWR, France. Iron (II) chloride tetrahydrate $\left(\mathrm{FeCl}_{2} \cdot 4 \mathrm{H}_{2} \mathrm{O}\right)$, iron (III) chloride hexahydrate $\left(\mathrm{FeCl}_{3} \cdot 6 \mathrm{H}_{2} \mathrm{O}\right)$, and oleic acid were purchased from Merck. Octane, ammonium hydroxide, and chlorhydric acid were from Prolabo. The preparation of the described bioconjugates and antibodies (5-[4-(amino)phenylsulfonamide]-5-oxopentanoic acid (SA2BSA) and Ab155) was performed with the support of the ICTS (Infraestructuras Científico-Tecnológicas Singulares "NANBIOSIS" Spain), more specifically by the Custom Antibody Service (CAbS, CIBER-BBN, IQAC-CSIC). The immunoreagents for sulfapyridine (SPy) detection used for the development of the biosensor were described before [23]. All other chemicals were purchased from Sigma-Aldrich and were used as received. All electrochemical measurements were performed on a VMP3 electrochemical workstation.

\subsection{Preparation of Oil-in-Water Magnetic Emulsion}

The oil-in-water magnetic emulsion (ME) consisted of magnetite nanoparticles stabilized with oleic acid, octane, and dodecyl sodium sulfate and was prepared according to our previous work [20,24,25]. Before obtaining the ME, the superparamagnetic iron oxide nanoparticles (SPIONs) were synthetized by coprecipitation method. Firstly, a solution containing iron chloride salts (ratio $\left[\mathrm{Fe}^{3+}\right] /\left[\mathrm{Fe}^{2+}\right]=2$ ) was prepared. Then, concentrated ammonia was carefully added to this solution to produce magnetic nanoparticles. When the solution $\mathrm{pH}$ was around 9, oleic acid (stabilizing agent) was added to the dispersion under vigorous stirring. The SPIONs were extracted by introducing octane (organic phase) in the medium. Finally, the organic ferrofluid was collected by magnetic separation and filtered on a 1 $\mathrm{mm}$ porous nylon filter in order to eliminate aggregates, and it was concentrated by octane evaporation under vacuum until it achieved a solid content of about $70 \% \mathrm{wt}$.

Afterward, the organic ferrofluid was emulsified in an aqueous solution of a nonionic surfactant (Triton $\mathrm{X}-405$, at least $25 \mathrm{wt} \%$ in water) and sheared in a couette emulsifier in order to target submicron ferrofluid droplets. The sheared emulsion was recovered and then diluted in a water solution containing sodium dodecyl sulphate (SDS) $\left(2 \mathrm{~g} \mathrm{~L}^{-1}\right)$. Then, the oil-in-water magnetic emulsion was sorted under magnetic field in order to collect narrowly sized distributed droplets. Lastly, the magnetic emulsion was diluted until it achieved a total solid content of about $4 \% \mathrm{wt}$.

\subsection{Electrochemical Measurements}

The electrochemical measurements were made by using a multi-channel potentiostat (VMP3 Biologic Science Instrumentation, France). Cyclic voltammetry (CV) and electrochemical impedance spectroscopy (EIS) were applied to characterize the surface of WEs before and after bio-functionalization using $\mathrm{K}_{3}\left[\mathrm{Fe}(\mathrm{CN})_{6}\right] / \mathrm{K}_{4}\left[\mathrm{Fe}(\mathrm{CN})_{6}\right](5 \mathrm{mM})$ as the electrolyte in phosphate buffered saline (PBS, pH 7.4). $\mathrm{CV}$ measurements were made at potentials of $0.5 \mathrm{~V}$ to $-0.3 \mathrm{~V}$, scan rate of $80 \mathrm{mV} \mathrm{s}^{-1}$, and 3 cycles. EIS measurements were made at a potential of $0.228 \mathrm{~V}$, frequency of $200 \mathrm{kHz}$ to $200 \mathrm{mHz}$, and sinus amplitude of $25 \mathrm{mV}$.

\subsection{Fabrication of the Biosensor}

The Bio-MEMS, based on gold microelectrodes, was fabricated in collaboration with the National Centre of Microelectronic (CNM) in Spain. The detailed process of fabrication and the characterization of the microlectrode were previously published in our group [26]. Briefly, a silicon wafer of $100 \mathrm{~mm}$ diameter was used as a substrate. Silicon dioxide $\left(\mathrm{SiO}_{2}\right)$ was then grown up to $800 \mathrm{~nm}$ by wet thermal oxidation. Then, gold working microelectrodes were defined by deposition and patterning of a metal 
tri-layer of $\mathrm{Ti}(50 \mathrm{~nm}), \mathrm{Ni}(50 \mathrm{~nm})$, and $\mathrm{Au}(200 \mathrm{~nm})$. For the counter microelectrode, a bilayer of Ti (15 $\mathrm{nm})$ plus $\mathrm{Pt}(150 \mathrm{~nm})$ was deposited. Finally, for the reference integrated microelectrode, a bilayer of Ti (15 nm) plus Ag (150 nm) was deposited and patterned by lift-off. All microelectrodes dimensions and the process of fabrication were detailed in our previous work [26].

After the fabrication process, the wafer was diced to individual devices $4 \times 7 \mathrm{~mm}$ and was then glued to the PCB board (Figure 1b). Micro pads of all microelectrodes were then electrically connected to the PCB board (Figure 1c) and then were passivated with epoxy resin (Ep-Tek H70E-2LC) to protect all electrical connections (Figure 1c) [26].

a)

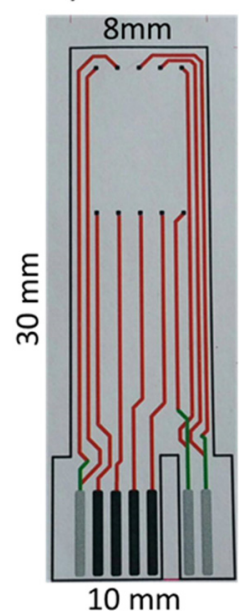

b)

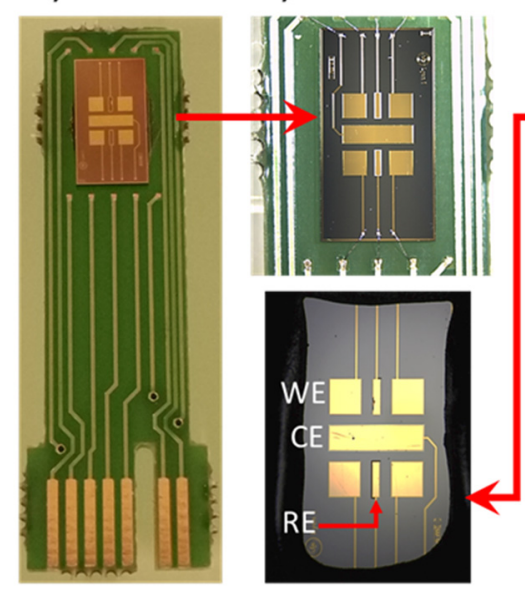

d)

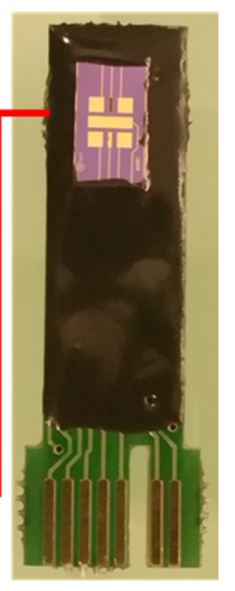

Figure 1. Optical microscope images of (a) printed circuit board (PCB) dimensions, (b) transducers glued onto the PCB board, (c) electrical connections, and (d) passivation with epoxy resin

Working electrodes (WEs) were cleaned by rinsing them with ethanol for 5 minutes, and then they were properly rinsed with deionized water. They were then dried under steam of nitrogen. The surface WEs were then cleaned from organic contaminants by using $\mathrm{UV} / \mathrm{O}_{3}$ (UV/Ozone ProCleanerTM, BioForce Nanosciences) for $30 \mathrm{~min}$. The device was connected to the potentiostat VMP3. Analysis was monitored and modeled using the EC-Lab software.

Electrochemical deposition of 4-aminophenylacetic acid $98 \%$ (CMA) was made by using $5 \mathrm{mM}$ of CMA in water with sodium nitrite $15 \mathrm{mM}$ and $\mathrm{HCl} 15 \mathrm{mM}$. Both sodium nitrite and $\mathrm{HCl}$ solutions were added to the solution of CMA and kept in an ice bath for $15 \mathrm{~min}$. This electrode preparation approach was adapted from that reported by Allongue et al. (1997) [27]. The final solution was kept at $0{ }^{\circ} \mathrm{C}$ and immediately used. The reductive absorption of the salt onto the electrode was achieved by four repetitive scans of $\mathrm{CV}$ between 0.3 and $-1.0 \mathrm{~V}$ at $200 \mathrm{mV} \mathrm{s}^{-1}$. Figure 2 shows a schematic illustration of CMA deposition onto gold WEs. 


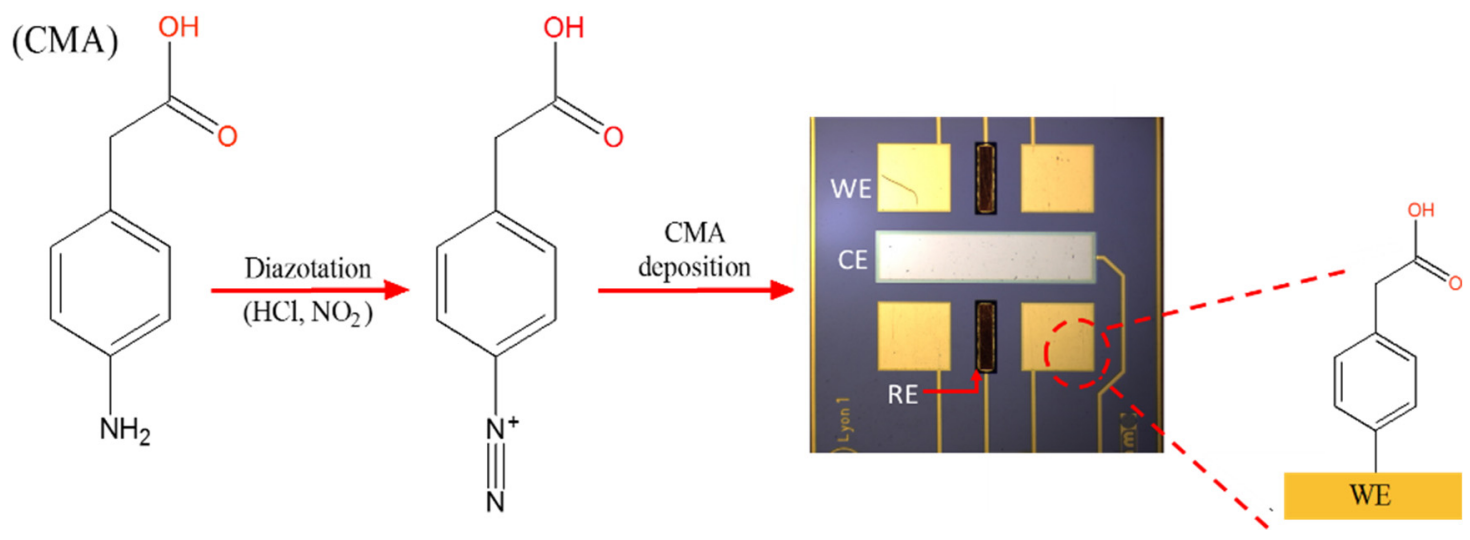

Figure 2. Schematic representation of surface gold working electrode modification with 4-aminophenylacetic acid (CMA). WEs, CE, and RE are working electrode, counter electrode, and reference electrode, respectively.

\subsection{Process for Biosensor Bio-Functionalization}

A solution of EDC $0.4 \mathrm{M}$ and NHS $0.1 \mathrm{M}$ was made up in $1 \mathrm{~mL}$ of anhydrous ethanol, and the device was incubated in a $2 \mathrm{~mL}$ Eppendorf for $1 \mathrm{~h}$ at room temperature. After this time, the device was rinsed with $\mathrm{HCl} 0.1 \mathrm{M}$ and dried with nitrogen stream carefully. Immediately, the CMA modified WEs were incubated in $60 \mu \mathrm{L}$ of SA2BSA antigens at $100 \mu \mathrm{g} \mathrm{mL}{ }^{-1}$ for $1 \mathrm{~h}$ at room temperature. Then, the microelectrodes were rinsed with PBS and incubated in $0.1 \%$ solution of ethanolamine (ETA) in PBS for $20 \mathrm{~min}$ at room temperature. This deactivated all remaining carboxylic activated sites. This step was necessary in order to prevent non-specific binding. At this stage, the biosensors were ready for antibodies detection.

\subsection{Preparation of Magnetic Nanoparticles}

The magnetic nanoparticles (MNPs) were prepared using the strategy that consisted of an oil-in-water magnetic emulsion as seed in the emulsion polymerization of styrene (St) and divinylbenzene (DVB). The polymerization was carried out in a $60 \mathrm{~mL}$ three-necked double wall glass reactor made up of glass anchor type stirrer, a reflux condenser, and a nitrogen inlet. The temperature was controlled at $70^{\circ} \mathrm{C}$ by using a thermal bath.

Firstly, the supernatant of the magnetic emulsion $(50 \mathrm{~mL})$ was removed after $5 \mathrm{~min}$ of magnetic separation. After that, the remaining magnetic particles were stabilized with the same volume of $1 \mathrm{~g} \mathrm{~L}^{-1}$ aqueous solution of dodecyl sodium sulfate (SDS) and introduced into the reactor. Then, the ME was purged with nitrogen for $1 \mathrm{~h}$ under stirring of $300 \mathrm{rpm}$ to remove the residual oxygen. Afterward, a total of $1.2 \mathrm{~mL}$ of monomers (with ratio of $20 \mathrm{wt} . \% \mathrm{St}$ and $80 \mathrm{wt} . \% \mathrm{DVB}$ ) was charged at once into the reactor containing the $\mathrm{ME}$ being kept under continuous stirring during $60 \mathrm{~min}$. The radical polymerization started after adding $2 \mathrm{wt} . \%$ (with respect to the total weight of monomers) of 4,4'-azobis(4-cyanopentanoic acid) (ACPA) solubilized in a solution of $0.1 \mathrm{~mol} \mathrm{~L}^{-1}$ sodium hydroxide with SDS. The radical polymerization was conducted at constant mechanical stirring ( $300 \mathrm{rpm}$ ) and was left overnight for $24 \mathrm{~h}$. A schematic representation of magnetic nanoparticles preparation is shown in Figure 3. 


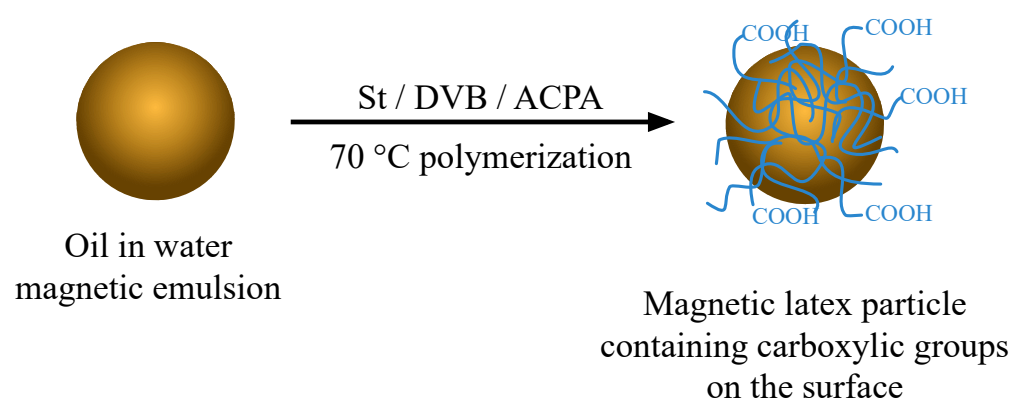

Figure 3. Schematic representation of magnetic nanoparticles preparation.

\subsection{Preparation of the MNP-Ab Labels}

In order to increase the sensitivity of the biosensor, the antibodies Ab155 were immobilized onto MNP by the carbodiimide chemistry (Figure 4). The general procedure was based on our previous work [23]. Briefly, a vial of $1 \mathrm{~mL}$ of MNP was placed in a magnetic rack for $5 \mathrm{~min}$ to immobilize the MNP and to remove the support solution. Then, $1 \mathrm{~mL}$ of PBS was added in order to wash the MNP. This operation was repeated three times to ensure that all surfactants were removed.

The carboxylic groups from the MNP were activated after treatment with a mixture of EDC $0.1 \mathrm{M}$ and NHS $0.1 \mathrm{M}$ and prepared in anhydrous ethanol for $90 \mathrm{~min}$ with continuous stirring at room temperature. After this time, the MNPs were rinsed by using a magnetic rack three times with $\mathrm{HCl} 1 \mathrm{mM}$ in order to keep the activity of carboxylic acid. Then, $500 \mu \mathrm{L}$ of a purified antibody Ab155 (100 $\mu \mathrm{g} \mathrm{mL}^{-1}$ in PBS $10 \mathrm{mM}$ ) was added to the activated MNP with stirring (500 rpm at room temperature) for 2-3 hours. The Ab155 was previously purified from the antisera As155 by ammonium sulfate precipitation at $40 \%$ of total saturation. Finally, the vial of Ab155-modified MNP was washed with PBS 3 times using the magnetic rack and stored in PBS at $4{ }^{\circ} \mathrm{C}$. The antibody reacted with the activated $\mathrm{COOH}$ by the free accessible lysines of the antibody, as shown in Figure 4.

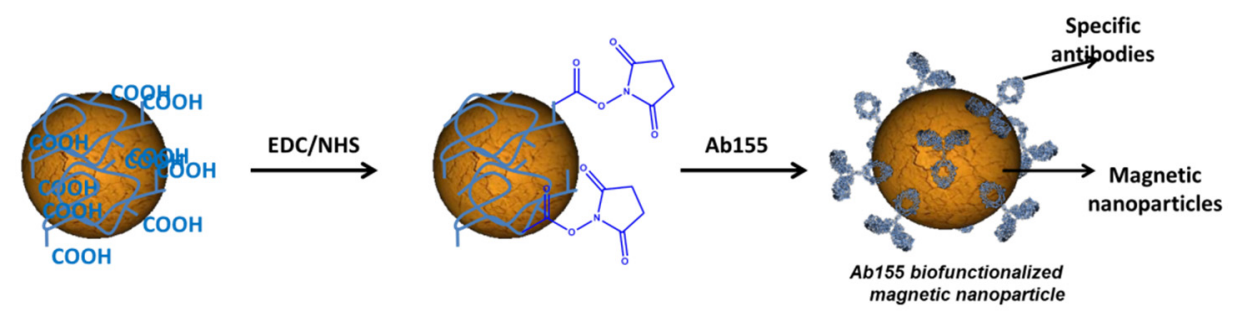

Figure 4. Chemical strategy for the biofunctionalization of Ab155 using carbodiimide chemistry to the magnetic nanoparticles (MNPs).

\subsection{Magneto-ELISA for MNP-Ab155/SA7-HRP}

Horseradish peroxidase (HRP) labeled with a specific enzymatic tracer SA7-HRP for Ab155 ( $2 \mu \mathrm{g} \mathrm{mL}^{-1}$ in PBS-tween) was mixed with a suspension of different concentration of the biomodified magnetic beads $\left(100 \mu \mathrm{L}\right.$, from 100 to $0 \mu \mathrm{g} \mathrm{mL}^{-1}$ of Ab155-MNP). The immunological reaction was allowed to proceed for $30 \mathrm{~min}$ at RT with vigorous shaking. The magnetic beads were then washed with PBST (150 $\mu \mathrm{L}$, three times), and the substrate solution $(100 \mu \mathrm{L}, 0.01 \%$ tétraméthylbenzidine (TMB) and $0.004 \% \mathrm{H}_{2} \mathrm{O}_{2}$ in citrate buffer $0.05 \mathrm{M} \mathrm{pH} 5.5$ ) was added and incubated again for $30 \mathrm{~min}$ at RT. The enzymatic reaction was stopped by adding $2 \mathrm{M} \mathrm{H}_{2} \mathrm{SO}_{4}(50 \mu \mathrm{L})$. Finally, the supernatants were removed from the magnetic beads and then added to a different plate for measuring the absorbance at $450 \mathrm{~nm}$. 


\section{Results}

\subsection{Characterization of the Magnetic Nanoparticles}

The characterization of the produced nanoparticles was performed by transmission electron microscopy (TEM), dynamic light scattering (DLS), zeta potential measurement, and thermal gravimetric analysis (TGA). Before polymerization, the average particle size of ME was approximately $237 \mathrm{~nm}$ [20]. As we expected, after polymerization, the average particle size increased up to $296 \mathrm{~nm}$ due to addition of polymer shell (See Figure 5). However, due to the presence of such a polymer shell, the values of zeta potential decreased. In a $\mathrm{pH}$ ranging from four to nine, the particles showed zeta potential values of -40 to $-50 \mathrm{mV}$ and -28 to $-35 \mathrm{mV}$ for magnetic emulsion and core-shell particles, respectively. The highest zeta potential values for ME was associated with the presence of the strong acid sulfate groups $\left(-\mathrm{SO}_{4}{ }^{-}\right)$ emanating from SDS (stabilizing agent) of the magnetic emulsion. However, after polymerization, the ME surface was covered by non-charged molecules, and only ACPA could contribute to the surface charge due to the presence of $\mathrm{COOH}$ moieties.

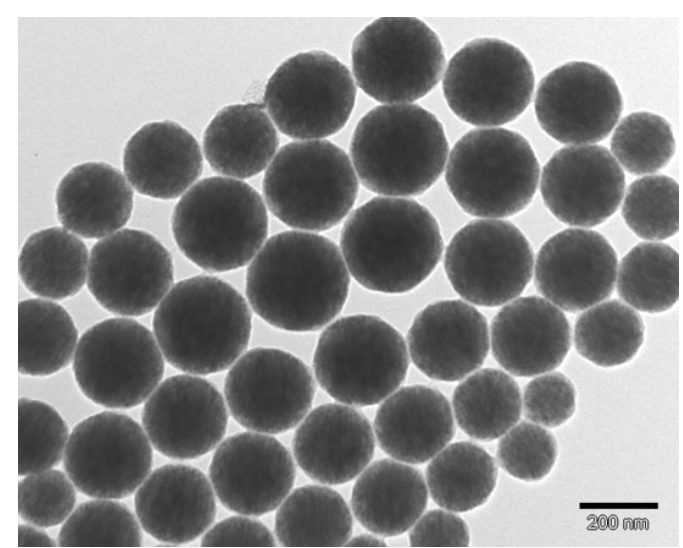

(A)

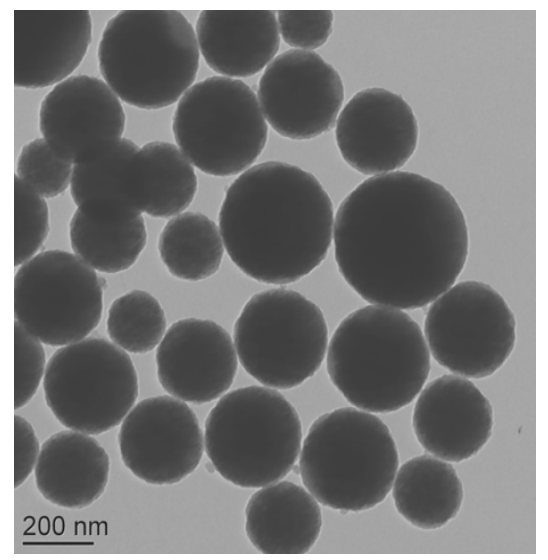

(B)

Figure 5. TEM images of: (A) magnetic emulsion, (B) samples (with core-shell like morphology containing $\mathrm{COOH}$ moieties from 4,4'-azobis(4-cyanopentanoic acid) (ACPA) obtained after seed-polymerization using $20 \mathrm{wt} . \%$ St and $80 \mathrm{wt} . \%$ divinylbenzene (DVB).

Once the final bioconjugates were purified, a characterization of the biofunctionality was required. The best way to know the functionality of the Ab-MNPs conjugate was by magneto-ELISA (Figure 6). This method consisted of testing the Ab-MNPs conjugate with an enzymatic tracer that had an affinity for the immobilized antibody. After a period of incubation and washing, a substrate was added in order to obtain the colorimetric signal from the enzyme, which was bound to the antibody. The antibody amount immobilized onto the surface was quantified and found to be $100 \mu \mathrm{g} \mathrm{mL}^{-1}$ for batch preparation. The magneto-ELISA let us conclude that not only was the immobilization was successful but also the antibody was functional and the obtained signal was specific. 


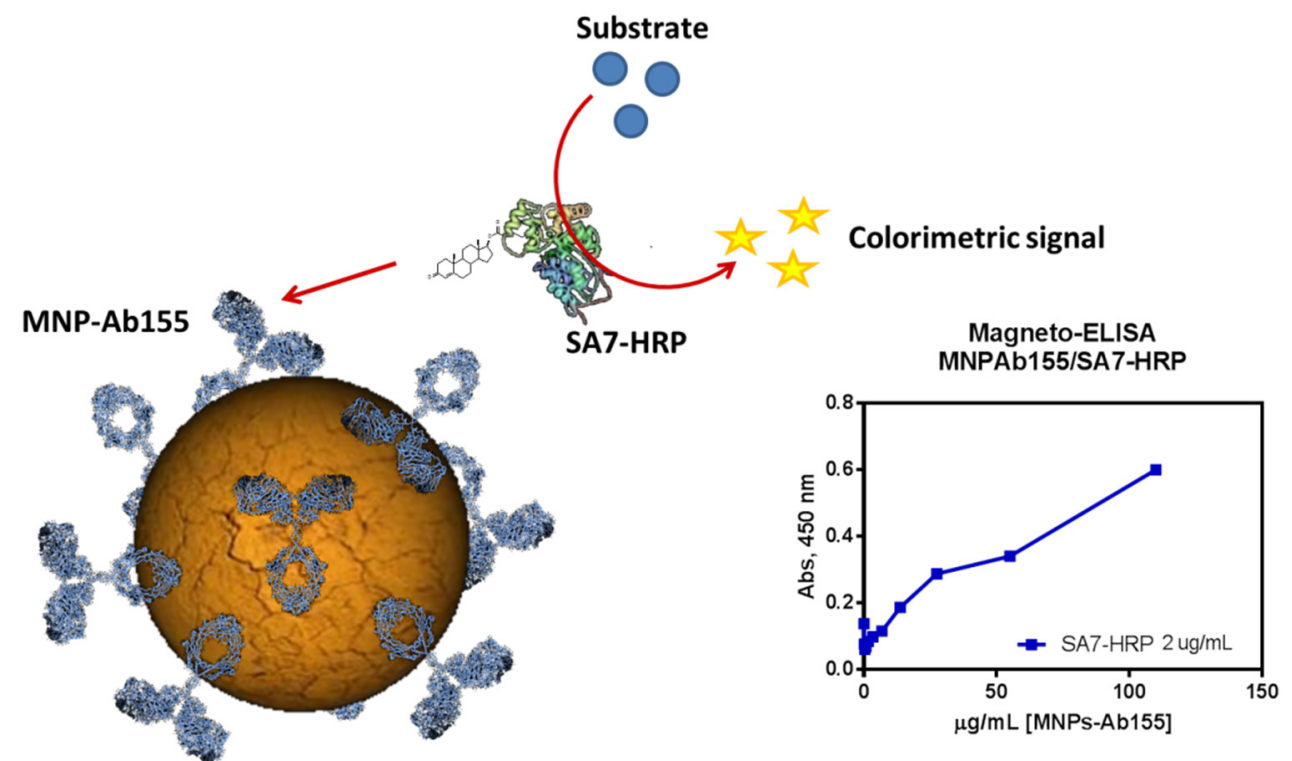

Figure 6. Representation of a magneto-ELISA and the results obtained for MNPs coupled with Ab155 (specific for SA7-HRP and Sulfonamides).

\subsection{Characterization of CMA-Modified Electrode.}

The reductive adsorption of the salt onto the electrode was achieved by four repetitive scans of $\mathrm{CV}$ between 0.3 and $-1.0 \mathrm{~V}$ at $200 \mathrm{mV} \mathrm{s}^{-1}$. The initial cycle in Figure 7A shows a broad and irreversible cathodic wave with a potential peak at $-0.9 \mathrm{~V}$, which indicates diazotized CMA attachment onto the gold surface by diazonium salt reduction. The cathodic current was remarkably weakened in the successive scans. These were attributed to the large passivation area of the microelectrode. This statement was confirmed by CV before and after gold WEs modification (Figure 7B), where an important decrease in peak-to-peak of the CV cycle was seen when compared to the bare gold microelectrodes.
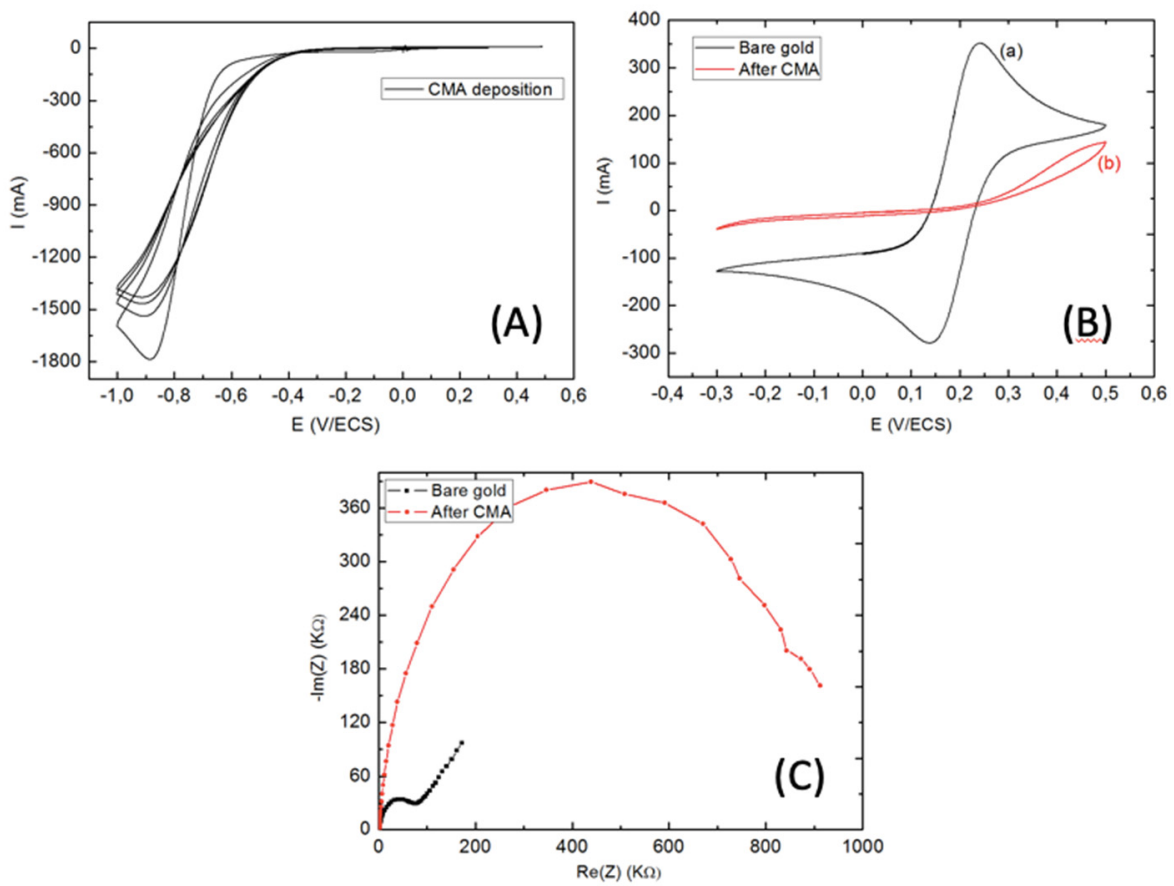

Figure 7. (A) Cyclic voltammetry (CV) for electrodeposition of CMA. Four repetitive potential cycles from $0.3 \mathrm{~V}$ to $-1.0 \mathrm{~V}$ with a scan rate of $0.2 \mathrm{~V} \mathrm{~s}^{-1}$. (B) Cyclic voltammetry scan, (C) electrochemical impedance spectroscopy for bare gold WE (black line), and CMA immobilized onto the WE (red line). 
These results were confirmed by EIS analysis before and after CMA deposition (Figure 7C). Therefore, the first semi-circle of Nyquist plot diagram corresponded to impedance of gold WEs, which was too weak when compared to CMA modified WEs. This was related to the passivation of WEs with the CMA layer, which increased the transfer charge resistance $\left(\mathrm{R}_{\mathrm{tc}}\right)$ between the modified WEs and the electrolyte solution.

\subsection{Titration Assay for Ab155 to SA2BSA Coated Wes by EIS}

Electrochemical impedance spectroscopy (EIS) was made for the coated-antigens SA2BSA gold WEs (Figure 8). Here, the first semi-circle of Nyquist plot (black line) corresponded to the coating antigens without any detection. In order to detect Ab155 antibodies, the biosensors were rinsed with PBS and incubated in $60 \mu \mathrm{L}$ of antibodies aqueous solution of Ab155 at different concentrations ranging from $1 \mu \mathrm{g} \mathrm{mL}{ }^{-1}$ to $50 \mu \mathrm{g} \mathrm{mL}^{-1}$ for $30 \mathrm{~min}$, then rinsed with PBS and analyzed with EIS.

The subsequent Nyquist plot semi-circles were shifted from the first, indicating an increase of the transfer charge resistance $\left(R_{t c}\right)$. As the Rtc became higher, the greater the concentration of antibodies Ab155 was.

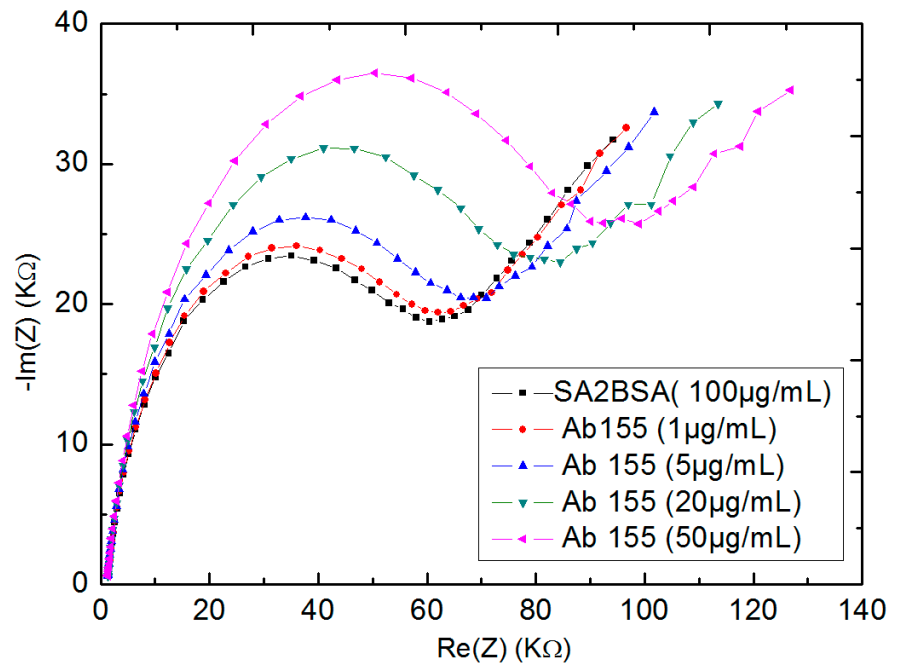

Figure 8. Electrochemical impedance spectroscopy (EIS) measurements of different concentrations of Ab155 with fixed concentration of SA2BSA.

\subsection{Competitive Assay for the Detection of Sulfapyridine (SPY) Usin SA2-BSA Coated Electrode with Ab155}

After showing the interactivity of the coating antigens with different concentrations of Ab155 antibodies, the same principle of EIS detection was applied in this section by using Ab155 antibodies with another antigen sulfapyridine (SPY). The SPY is also specific to Ab155 antibodies. Here, a mixture of $20 \mu \mathrm{L}$ of fixed concentration of Ab155 antibodies (50 $\mathrm{g} \mathrm{mL}^{-1}$ ) was added to $20 \mu \mathrm{L}$ of different concentrations of SPY $40 \mu \mathrm{M}, 4 \mu \mathrm{M}, 2 \mathrm{nM}$, and finally $0 \mathrm{M}$ (only PBS), respectively. For each concentration, the two solutions ( $20 \mu \mathrm{L}$ of $\mathrm{Ab} 155$ and $20 \mu \mathrm{L}$ of SPY) were then allowed to incubate the SA2BSA modified biosensor for $30 \mathrm{~min}$ and kept at $4{ }^{\circ} \mathrm{C}$. After each incubation, the surface of microelectrodes was rinsed with PBS and analyzed by EIS measurements. Here, there was a competition between SPY and SA2BSA to detect Ab155 antibodies.

Figure 9 shows the Nyquist plot semi-circles obtained for $50 \mu \mathrm{g} \mathrm{mL} \mathrm{m}^{-1}$ of Ab155 in the presence of different concentrations of SPY. The first and the second semi-circles corresponded to the bare gold (black line) and the coating antigens SA2BSA (blue line), respectively. After the first incubation of the biosensor within Ab155 and $40 \mu \mathrm{M}$ of SPY (the third Nyquist plot semi-circle), we observed a shift showing a detection of Ab155 antibodies by SA2BSA. In this case, the concentration of SPY was too high, which meant a large amount of Ab155 reacted with SPY, while the rest was attached to the coating antigens SA2BSA. By decreasing the concentration of SPY, there were more antibodies Ab155 
free in the solution, which have may reacted with SA2BSA. This was confirmed by the increase of Nyquist plot semi-circles. Finally, when the biosensor was incubated only in Ab155 antibodies with PBS, the totality of the antibodies reacted with the coating antigen SA2BSA, thus giving a big shift between Nyquist plot semi-circles.

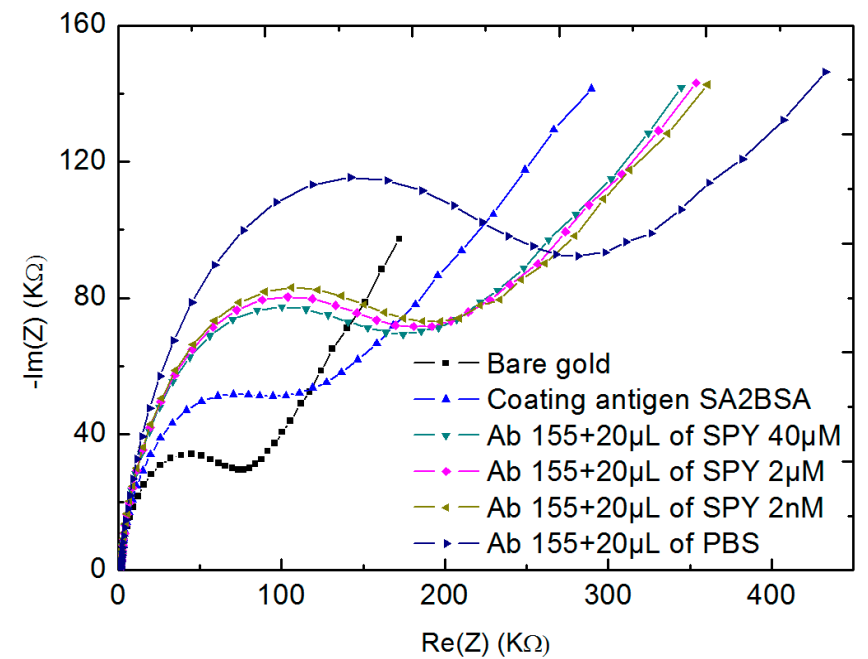

Figure 9. EIS measurements of Ab155 with different concentrations of SPY (40 $\mu \mathrm{M}, 4 \mu \mathrm{M}, 2 \mathrm{nM})$ and phosphate-buffered saline (PBS) only.

\subsection{Competitive Assay for the Detection of Sulfapyridine (SPY) Usin SA2-BSA Coated Electrode with} MNP-Ab155

Firstly, the immobilization of the coating antigen with $100 \mu \mathrm{g} \mathrm{mL} \mathrm{m}^{-1}$ solution of SA2BSA was made onto WEs surface, as explained in Section 2.4. Afterward, the Ab155-modified MNP with fixed quantity of $20 \mu \mathrm{L}$ was mixed with different concentrations of SPY ( $40 \mu \mathrm{M}, 4 \mu \mathrm{M}$, and $2 \mathrm{nM})$ and finally only with PBS. Here, the same principle of competitive detection between SPY and SA2BSA was applied (Figure 10). By decreasing the concentration of SPY, the shift between Nyquist plot semi-circles increased. However, when compared to the competitive detection without MNP, this shift was more significant, especially for the concentrations $40 \mu \mathrm{M}, 2 \mu \mathrm{M}$, and $2 \mathrm{nM}$. This result was associated with the high number of antibodies present on the MNP surface.

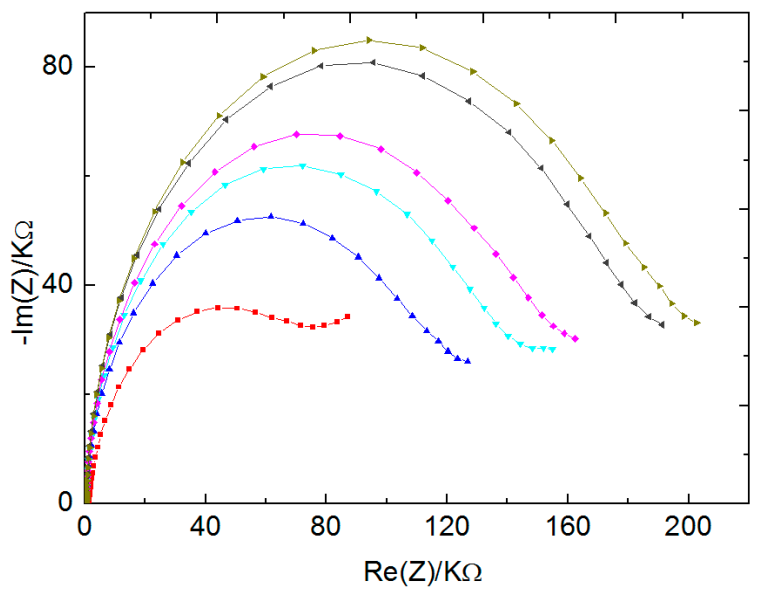

Figure 10. EIS measurements of fixed quantity of Ab 155 modified magnetic latex particles $(20 \mu \mathrm{L})$ against different concentrations of sulfapyridine (SPY) $(40 \mu \mathrm{M}, 4 \mu \mathrm{M}, 2 \mathrm{nM})$ and PBS only. Bare gold

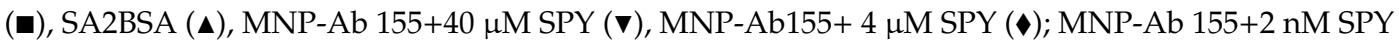
(४), and MNP-Ab 155+Only PBS (•). 
EIS measurements were repeated at least four times, as we had four Wes, and Nyquist plots were fitted for both Figures 9 and 10 concerning the detection of Ab155 with and without MNP by using the equivalent circuit (Figure 11A inset). Here, Rs indicated electrolyte solution resistance, $Q$ was the constant phase element that corresponded to the charge distribution at the interface electrode/electrolyte, $R_{c t}$ (which was in parallel with $Q$ ) was the resistance of charge transfer, and finally, W corresponded to Warburg impedance, which is related to the diffusion phenomenon at the electrode-electrolyte interface $[10,28]$.

After calculating fitting parameters from the applied equivalent circuit, it was clearly evidenced that there was more linearity for the biosensor with Ab155 modified MNP (Figure 11B) when compared to competitive detection without magnetic nanoparticles (Figure 11A). This result indicated that the sensitivity of the biosensor increased and provides a better understanding of the Ab155 interaction in the presence of SA2BSA and SPY at the same time.

In this study, we had the reverse system of normal detection of biosensors. Here, as the response of the biosensors was higher, the less contamination there was, and vice versa. Indeed, when the response of the biosensor was too weak, this meant that there was an important concentration of SPY that saturated all the antibodies Ab155, such as in the case of the sample contaminated with SPY. On the other hand, if the response of the biosensor was too high, this meant that all the antibodies were collected with the coating antigens SA2BSA, such as in the presence of a sample without contamination or one that contained a weak amount of SPY.
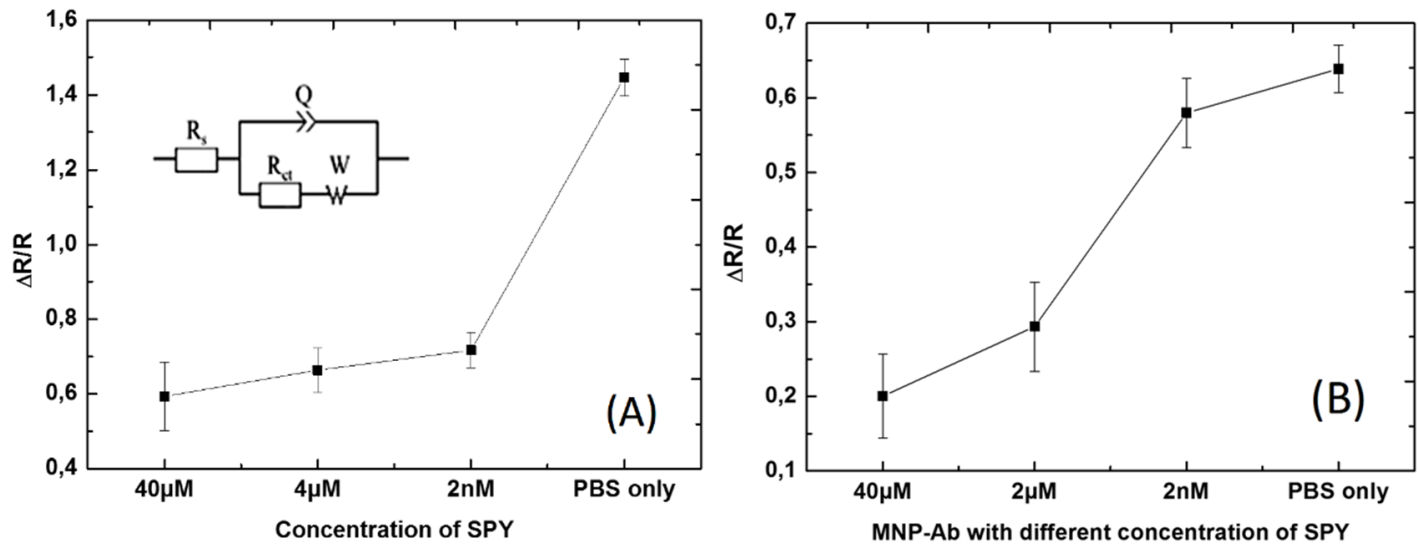

Figure 11. Graphical representation of fixed concentration of SA2BSA and Ab155 without magnetic nanoparticles (A) and with magnetic nanoparticles (B).

\section{Conclusions}

In this article, we reported the sensitivity of the synthetized biosensor using the application of competitive assay by immobilized fixed concentration of SA2BSA $\left(100 \mu \mathrm{g} \mathrm{mL}^{-1}\right)$ and fixed concentration of Ab155 (50 $\mathrm{g} \mathrm{mL}^{-1}$ ) against different concentrations of SPY, such as $40 \mu \mathrm{M}, 4 \mu \mathrm{M}, 2 \mathrm{nM}$, and finally only with PBS, with and without use of magnetic nanoparticles. Using CV and EIS, the microelectrodes were characterized for the bare gold, surface-functionalized CMA, immobilized SA2BSA, and fixed concentration of MNP containing immobilized Ab155 with different concentrations of SPY.

The Nyquist plots showed a stepwise increase of $R_{c t}$ in both cases (Ab155 with and without magnetic nanoparticles that contain immobilized Ab155 with different concentrations of SPY). However, after calculations from fitting parameters and drawing graphs, it could be clearly observed that there was more linearity while using magnetic nanoparticles compared to that without their use. This indicated the increase in sensitivity of the biosensor as compared to competitive assay without magnetic nanoparticles.

Author Contributions: T.J. designed, planned, performed and analyzed the major experiments. E.T.T.-N. and A.B., A.S., J.-P.S., J.B. and M.-P.M. Marco were in charge of characterization and provision of the immunoreagents 
for SA detection. N.L. and A.E. (Abdelhamid Elaissari) revised and assisted in editing the manuscript. A.E. (Abdelhamid Errachid) and N.Z. are project supervisors and overview the research progress. All authors have read and agreed to the published version of the manuscript.

Funding: The authors acknowledge the financial support from the projects European Communities Seventh Framework Program: SEA-on-a-CHIP (FP7-OCEAN-2013) under the grant agreement $\mathrm{N}^{\circ} 614168$, and funding from the European Union's Horizon 2020 research and innovation program entitled KardiaTool under grant agreement $\mathrm{N}^{\circ}$ 643694, and the fellowship from Science Without Borders program-Conselho Nacional de Desenvolvimento Ciêntífico Tenológico (CNPq)-Brazil grant N² 249056/2013-5.

Conflicts of Interest: The authors declare no conflict of interest.

\section{References}

1. Rosi-Marshall, E.J.; Kelly, J.J. Antibiotic Stewardship Should Consider Environmental Fate of Antibiotics. Environ. Sci. Technol. 2015, 49, 5257-5258. [CrossRef] [PubMed]

2. Ge, L.; Zhang, P.; Halsall, C.; Li, Y.; Chen, C.-E.; Li, J.; Sun, H.; Yao, Z. The importance of reactive oxygen species on the aqueous phototransformation of sulfonamide antibiotics: Kinetics, pathways, and comparisons with direct photolysis. Water Res. 2019, 149, 243-250. [CrossRef] [PubMed]

3. Acosta-Rangel, A.; Sánchez-Polo, M.; Rozalen, M.; Rivera-Utrilla, J.; Polo, A.M.S.; Mota, A.J. Comparative Study of the Oxidative Degradation of Different 4-Aminobenzene Sulfonamides in Aqueous Solution by Sulfite Activation in the Presence of Fe(0), Fe(II), Fe(III) Or Fe(VI). Water 2019, 11, 2332. [CrossRef]

4. Li, L.; Lin, Z.; Huang, Z.; Peng, A. Rapid detection of sulfaguanidine in fish by using a photonic crystal molecularly imprinted polymer. Food Chem. 2019, 281, 57-62. [CrossRef] [PubMed]

5. Yan, C.; Yang, Y.; Zhou, J.; Liu, M.; Nie, M.; Shi, H.; Gu, L. Antibiotics in the surface water of the Yangtze Estuary: Occurrence, distribution and risk assessment. Environ. Pollut. 2013, 175, 22-29. [CrossRef]

6. Pang, G.-F.; Cao, Y.-Z.; Zhang, J.-J.; Li, X.-M.; Li, Z.-Y.; Jia, G.-Q.; Fan, C.-L. Liquid chromatographyfluorescence detection for simultaneous analysis of sulfonamide residues in honey. Anal. Bioanal. Chem. 2003, 376, 534-541. [CrossRef]

7. Wang, Y.-C.; Hsieh, F.-C.; Wang, J.-L.; Shu, Y.-Y. Solvent pulse desorption on-line solid-phase extraction combined with high-performance liquid chromatographic determination of 14 sulfonamides in environmental water samples. Anal. Methods 2019, 11, 4370-4375. [CrossRef]

8. Georgiadis, D.-E.; Tsalbouris, A.; Kabir, A.; Furton, K.G.; Samanidou, V. Novel capsule phase microextraction in combination with high performance liquid chromatography with diode array detection for rapid monitoring of sulfonamide drugs in milk. J. Sep. Sci. 2019, 42, 1440-1450. [CrossRef]

9. Hassani, N.E.A.E.; Baraket, A.; Neto, E.T.T.; Lee, M.; Salvador, J.P.; Marco, M.-P.; Bausells, J.; Bari, N.E.; Bouchikhi, B.; Elaissari, A.; et al. Novel Strategy for Sulfapyridine Detection Using a Fully Integrated Bio-MEMS: Application to Honey Analysis. Procedia Technol. 2017, 27, 254-255. [CrossRef]

10. Hassani, N.E.A.E.; Baraket, A.; Boudjaoui, S.; Neto, E.T.T.; Bausells, J.; Bari, N.E.; Bouchikhi, B.; Elaissari, A.; Errachid, A.; Zine, N. Development and application of a novel electrochemical immunosensor for tetracycline screening in honey using a fully integrated electrochemical Bio-MEMS. Biosens. Bioelectron. 2019, 130, 330-337. [CrossRef]

11. Muriano, A.; Chabottaux, V.; Diserens, J.-M.; Granier, B.; Sanchez-Baeza, F.; Marco, M.-P. Rapid immunochemical analysis of the sulfonamide-sugar conjugated fraction of antibiotic contaminated honey samples. Food Chem. 2015, 178, 156-163. [CrossRef] [PubMed]

12. Valera, E.; Muriano, A.; Pividori, I.; Sánchez-Baeza, F.; Marco, M.-P. Development of a Coulombimetric immunosensor based on specific antibodies labeled with CdS nanoparticles for sulfonamide antibiotic residues analysis and its application to honey samples. Biosens. Bioelectron. 2013, 43, 211-217. [CrossRef] [PubMed]

13. Adrian, J.; Pasche, S.; Diserens, J.-M.; Sánchez-Baeza, F.; Gao, H.; Marco, M.-P.; Voirin, G. Waveguide interrogated optical immunosensor (WIOS) for detection of sulfonamide antibiotics in milk. Biosens. Bioelectron. 2009, 24, 3340-3346. [CrossRef] [PubMed]

14. Su, D.; Wu, K.; Krishna, V.D.; Klein, T.; Liu, J.; Feng, Y.; Perez, A.M.; Cheeran, M.C.-J.; Wang, J.-P. Detection of Influenza a Virus in Swine Nasal Swab Samples with a Wash-Free Magnetic Bioassay and a Handheld Giant Magnetoresistance Sensing System. Front. Microbiol. 2019, 10, 1077. [CrossRef] 
15. Klein, T.; Wang, W.; Yu, L.; Wu, K.; Boylan, K.L.M.; Vogel, R.I.; Skubitz, A.P.N.; Wang, J.-P. Development of a multiplexed giant magnetoresistive biosensor array prototype to quantify ovarian cancer biomarkers. Biosens. Bioelectron. 2019, 126, 301-307. [CrossRef]

16. Brezulianu, A.; Geman, O.; Zbancioc, M.D.; Hagan, M.; Aghion, C.; Hemanth, D.J.; Son, L.H. IoT Based Heart Activity Monitoring Using Inductive Sensors. Sensors 2019, 19, 3284. [CrossRef]

17. Azie, O.; Greenberg, Z.F.; Batich, C.D.; Dobson, J.P. Carbodiimide Conjugation of Latent Transforming Growth Factor $\beta 1$ to Superparamagnetic Iron Oxide Nanoparticles for Remote Activation. Int. J. Mol. Sci. 2019, 20, 3190. [CrossRef]

18. Hien, L.T.; Quynh, L.K.; Huyen, V.T.; Tu, B.D.; Hien, N.T.; Phuong, D.M.; Nhung, P.H.; Giang, D.T.H.; Duc, N.H. DNA-magnetic bead detection using disposable cards and the anisotropic magnetoresistive sensor. Adv. Nat. Sci. Nanosci. Nanotechnol. 2016, 7, 045006. [CrossRef]

19. Jamshaid, T.; Tenorio-Neto, E.T.; Eissa, M.M.; Zine, N.; Kunita, M.H.; Errachid, A.; Elaissari, A. Magnetic particles: From preparation to lab-on-a-chip, biosensors, microsystems and microfluidics applications. Trends Anal. Chem. 2016, 79, 344-362. [CrossRef]

20. Jamshaid, T.; Tenorio-Neto, E.T.; Eissa, M.; Zine, N.; Errachid, A.; Kunita, M.H.; Elaissari, A. Preparation and characterization of submicron hybrid magnetic latex particles. Polym. Adv. Technol. 2015, 26, 1102-1108. [CrossRef]

21. Tenório-Neto, E.T.; Baraket, A.; Kabbaj, D.; Zine, N.; Errachid, A.; Fessi, H.; Kunita, M.H.; Elaissari, A. Submicron magnetic core conducting polypyrrole polymer shell: Preparation and characterization. Mater. Sci. Eng. C 2016, 61, 688-694. [CrossRef] [PubMed]

22. Jamshaid, T.; Eissa, M.; Zine, N.; El-Salhi, A.E.; Ahmad, N.M.; Elaissari, A. Chapter 9: Soft Hybrid Nanoparticles: From Preparation to Biomedical Applications. In Soft Nanoparticles for Biomedical Applications; Royal Society of Chemistry: Edinburgh, UK, 2014; pp. 312-341.

23. Font, H.; Adrian, J.; Galve, R.; Estévez, M.-C.; Castellari, M.; Gratacós-Cubarsí, M.; Sánchez-Baeza, F.; Marco, M.-P. Immunochemical Assays for Direct Sulfonamide Antibiotic Detection In Milk and Hair Samples Using Antibody Derivatized Magnetic Nanoparticles. J. Agric. Food Chem. 2008, 56, 736-743. [CrossRef] [PubMed]

24. Montagne, F.; Mondain-Monval, O.; Pichot, C.; Mozzanega, H.; Elaissari, A. Preparation and characterization of narrow sized (o/w) magnetic emulsion. J. Magn. Magn. Mater. 2002, 250, 302-312. [CrossRef]

25. Montagne, F.; Braconnot, S.; Mondain-Monval, O.; Pichot, C.; Elaïssari, A. Colloidal and Physicochemical Characterization of Highly Magnetic O/W Magnetic Emulsions. J. Dispers. Sci. Technol. 2003, 24, 821-832. [CrossRef]

26. Gallardo-Gonzalez, J.; Baraket, A.; Boudjaoui, S.; Metzner, T.; Hauser, F.; Rößler, T.; Krause, S.; Zine, N.; Streklas, A.; Alcácer, A.; et al. A fully integrated passive microfluidic Lab-on-a-Chip for real-time electrochemical detection of ammonium: Sewage applications. Sci. Total Environ. 2019, 653, 1223-1230. [CrossRef]

27. Allongue, P.; Delamar, M.; Desbat, B.; Fagebaume, O.; Hitmi, R.; Pinson, J.; Savéant, J.-M. Covalent Modification of Carbon Surfaces by Aryl Radicals Generated from the Electrochemical Reduction of Diazonium Salts. J. Am. Chem. Soc. 1997, 119, 201-207. [CrossRef]

28. Lagonotte, P.; Ilie, V.A.R.; Martemianov, S.; Thomas, A. Extrapolation to zero frequency with first time constant of ferri-ferrocyanide/Pt interface using Foster equivalent circuit and factorized modelling. J. Electroanal. Chem. 2019, 839, 256-263. [CrossRef]

(C) 2020 by the authors. Licensee MDPI, Basel, Switzerland. This article is an open access article distributed under the terms and conditions of the Creative Commons Attribution (CC BY) license (http://creativecommons.org/licenses/by/4.0/). 